\title{
BMJ Global Health Reusability of filtering facepiece respirators after decontamination through drying and germicidal UV irradiation
}

\author{
David Vernez (D) , Jonathan Save, ${ }^{2}$ Anne Oppliger, ${ }^{1}$ Nicolas Concha-Lozano, ${ }^{3}$ \\ Nancy B Hopf, ${ }^{1}$ Hélène Niculita-Hirzel, ${ }^{1}$ Grégory Resch, ${ }^{2}$ Véronique Michaud, ${ }^{4}$ \\ Laurie Dorange-Pattoret, ${ }^{1}$ Nicole Charrière, ${ }^{1}$ Kiattisak Batsungnoen, ${ }^{1,5}$ \\ Guillaume Suarez ${ }^{1}$
}

To cite: Vernez D, Save J, Oppliger A, et al. Reusability of filtering facepiece respirators after decontamination through drying and germicidal UV irradiation. BMJ Global Health 2020;5:e003110. doi:10.1136/ bmjgh-2020-003110

Handling editor Seye Abimbola

- Additional material is published online only. To view, please visit the journal online (http://dx.doi.org/10.1136/ bmjgh-2020-003110).

Received 8 June 2020 Revised 16 September 2020 Accepted 18 September 2020

Check for updates

(C) Author(s) (or their employer(s)) 2020. Re-use permitted under CC BY-NC. No commercial re-use. See rights and permissions. Published by BMJ.

For numbered affiliations see end of article.

Correspondence to Professor David Vernez; david.vernez@unisante.ch
ABSTRACT
Introduction During pandemics, such as the SARSCoV-2, filtering facepiece respirators plays an essential role in protecting healthcare personnel. The recycling of respirators is possible in case of critical shortage, but it raises the question of the effectiveness of decontamination as well as the performance of the reused respirators. Method Disposable respirators were subjected to ultraviolet germicidal irradiation (UVGI) treatment at single or successive doses of $60 \mathrm{~mJ} / \mathrm{cm}^{2}$ after a short drying cycle $\left(30 \mathrm{~min}, 70^{\circ} \mathrm{C}\right)$. The germicidal efficacy of this treatment was tested by spiking respirators with two phages). The respirator performance was investigated by the following parameters: particle penetration $(\mathrm{NaCl}$ aerosol, 10-300 nm), scanning electron microscopy (SEM), Fourier-transform infrared spectroscopy (FTIR), differential scanning calorimetry and mechanical tensile tests. Results No viable phage particles were recovered from any of the respirators after decontamination (log reduction in virus titre $>3$ ), and no reduction in chemical or physical properties (SEM, particle penetrations $<5 \%-6 \%$ ) were observed. Increasing the UVGI dose 10-fold led to chemical alterations of the respirator filtration media (FTIR) but did not affect the physical properties (particle penetration), which was unaltered even at $3000 \mathrm{~mJ} / \mathrm{cm}^{2}$ (50 cycles). When respirators had been used by healthcare workers and undergone decontamination, they had particle respirators.

Conclusion This decontamination procedure is an attractive method for respirators in case of shortages during a SARS pandemic. A successful implementation requires a careful design and particle penetration performance control tests over the successive reuse cycles.

\section{INTRODUCTION}

The SARS-CoV-2 pandemic (COVID-19) that started at the end of 2019 led to a severe shortage of respirators such as the staphylococcal bacteriophages (vB_HSa_2002 and P66 penetration significantly greater than never donned

\section{Key questions}

What is already known?

- N95 or FFP2 disposable respirators are the most common respiratory protection devices used in healthcare settings to prevent contamination from airborne aerosols.

- The decontamination and recycling of respirators is an alternative in case of shortage, provided that the procedure is balanced to allow sufficient disinfection with the least possible impairment of the properties of the respirators.

What are the new findings?

- Decontamination through drying and a UV irradiation of $60 \mathrm{~mJ} / \mathrm{cm}^{2}$ was sufficient to ensure decontamination ( $>3$ log reduction in virus titre) without mechanical or filtration performance impairment of the respirator.

- Wearing the respirators causes a greater decrease in penetration efficiency than the disinfection cycle.

What do the new findings imply?

- In case of shortage, respirators can be recycled using drying and germicidal UV, which is relatively simple and inexpensive procedure.

- The integrity and penetration efficiency of the respirators during disinfection-recycling cycles must be monitored.

filtering facepiece respirators (FFRs) in Europe. This respirator shortage was caused by the tremendous need in protecting civilians and healthcare workers from airborne SARS-CoV-2. Infection control procedures call for disposable single-use FFR to avoid cross-contamination.

Respirators are rated according to percentage of penetration to aerosols, according to the labels FFP1-FFP2-FFP3 (EU Standard) and N95-N99-N100 (US standard). 
The most common respiratory protection used in healthcare settings are disposable FFP2 and N95 respirators and are capable of capturing $\geq 94 \%$ and $\geq 95 \%$, respectively, of aerosols in submicron range. ${ }^{12}$ Contrastingly, surgical masks do not provide respiratory protection from small airborne particles due to their loose fit and low filtration capacity. ${ }^{3}$ FFR are negative pressure air-purifying particulate respirators that differ from other respirators because the filtering media itself is the respirator. These disposable respirators are not recommended for reuse and should only be considered in a situation of critical shortage. One recommendation of respirator reuse during the COVID-19 pandemic is to provide one respirator per day for each healthcare worker who may be in direct contact with infected patients. ${ }^{5}$ This recommendation is based on the persistence of SARS-CoV-2 up to 72 hours on different surfaces. ${ }^{6}$ Decontamination of disposable FFR is the last resort. Appropriate methods need to be developed that inactivate viral particles, are harmless to the user and do not significantly compromise respirator filtering capacity. ${ }^{7}$

Several methods have been evaluated for their efficiency in decontaminating FFR such as autoclaving, steam generated by heat or microwaves, ethylene oxide, vaporised hydrogen peroxide and bleach. Moreover, a $>4$ $\log$ reductions in viable viral particles has been obtained after decontamination of H1N1 influenza-contaminated and $\mathrm{H} 5 \mathrm{~N} 1$ avian influenza-contaminated FFR via ultraviolet germicidal irradiation (UVGI) with a dose of 1440-1800 mJ $/ \mathrm{cm}^{2}{ }^{89}{ }^{9}$ A similar $\log$ reduction has been observed with a dose of $1800 \mathrm{~mJ} / \mathrm{cm}^{2}$ on the MS2 coliphage, ${ }^{10}$ but a $3-\log$ reduction was already achieved with a $30 \mathrm{~mJ} / \mathrm{cm}^{2}$ UVGI dose. ${ }^{11}$

Advantages of UVGI systems are the setup flexibility, short treatment time, facility of dosage and the absence of residual disinfecting agent after treatment. The UVGI treatment is less aggressive than other disinfection methods used in the hospital sector (eg, autoclaving or bleach), thus limiting damage to disposable respirators. ${ }^{12}$ Nevertheless, UVGI treatment is one of the germicidal procedures frequently used in the hospital and biological field. Other 'softer' disinfection methods, such as drying at medium temperature (typically between $70^{\circ} \mathrm{C}$ and $90^{\circ} \mathrm{C}$ ), have been suggested to deactivate the SARS-CoV-2. ${ }^{13-15}$ Arguably, drying and storing the respirators for a few days could be sufficient to deactivate the coronavirus, which cannot survive indefinitely outside the human body. However, the disadvantage of the latter methods when used alone is they do not necessarily eliminate other pathogens that may be present. Moreover, a recent review highlighted UVGI as one of the most promising decontamination methods for N95 FFRs. ${ }^{16}$

The effects of UVGI on respirator appearance, airflow resistance (breathability), particle filtration efficiency (penetration rate) and in one instance fit, have been studied in detail for multiple decontamination cycles. No significant effects were found for UVGI doses of 176-181 mJ/ $\mathrm{cm}^{2}$ after a $30 \mathrm{~min}$ irradiance ( $15 \mathrm{~min}$ each side) ${ }^{17}$ as well as for UVGI doses of $1620 \mathrm{~mJ} / \mathrm{cm}^{2}$ (each side) in particular for particle penetration and airflow resistance of different models of FFR. ${ }^{18}$ Only at extreme UVGI doses (120 000 to $950000 \mathrm{~mJ} / \mathrm{cm}^{2}$ ) a slight effect on strength, particle penetration (1.25\% increase) and airflow resistance (below $5 \%$ ) of the material was observed..$^{19}$ However, no study has yet demonstrated simultaneously that a treatment was efficient in decontaminating FFRs while maintaining its physical integrity over multiple decontamination cycles.

By using a protocol similar to a reference protocol developed at the University of Nebraska, USA, ${ }^{20}$ our aim was to test a decontamination procedure involving drying and germicidal UV ensuring germicidal efficacy while being low enough to avoid a physical or chemical alteration of the filter medium and allowing multiple recycling treatments.

\section{METHODS}

The full description of the methods and the experimental setting used is in the online supplemental material. Our method is based on a procedure developed by the University of Nebraska. ${ }^{20}$ Briefly, the decontamination procedure consisted of subjecting disposable FFP2 respirators (3M 6923 and 1862, 3M, Germany) to a drying cycle (oven temperature at $70^{\circ} \mathrm{C}$ for $30 \mathrm{~min}$ ) and subsequently exposing them to germicidal treatment with UVC. The respirators were suspended in a rotating circulating rack and irradiated for $4 \mathrm{~min}$ at an irradiance of $0.25 \mathrm{~mW} / \mathrm{cm}^{2}$ corresponding to a dose of $60 \mathrm{~mJ} / \mathrm{cm}^{2}$ (UVC, $254 \mathrm{~nm}$ ). The respirators were irradiated homogeneously by multidirectional irradiance set-up by the distribution of several UVC light sources $(n=10)$ and the presence of reflective walls in the chamber.

The effectiveness of the decontamination procedure was tested using two Staphylococcus aureus' bacteriophages (vB_HSa_2002 and P66 phages), belonging to the family of double-stranded DNA viruses. A count of viable phage particles on contaminated respirators subjected to germicidal treatment was compared with controls (spiked respirators that were not treated). The effect on the integrity of the respirators after successive decontamination cycles was assessed by increasing the UV doses from $60 \mathrm{~mJ}$ up to 3000 $\mathrm{mJ} / \mathrm{cm}^{2}$ (corresponding to 50 cycles). Physical and chemical alterations were investigated through scanning electron microscopy (SEM), Fourier-transform infrared spectroscopy (FTIR) and a fine particle penetration test $(\mathrm{NaCl}$ aerosol, $10-300 \mathrm{~nm}$ range). Respirators were also visually inspected after the decontamination procedure for possible mechanical damage (deformation, seal integrity and strings). Tests were conducted on both unused and used respirators, the latter being collected from frontline units from the Center for Primary Care and Public Health (Unisanté).

\section{RESULTS}

\section{Decontamination procedure efficiency and phage release} from FFR

No viable phage particles were recovered from any of the FFR extract solutions ( 12 masks and $n=2$ per mask) obtained from decontaminated FFR (table 1). 
Table 1 Viable Staphylococcus aureus phage particles measured on FFR before and after the decontamination process

\begin{tabular}{|c|c|c|c|c|c|}
\hline & \multicolumn{2}{|c|}{ vB_HSa_2002 } & \multicolumn{2}{|l|}{ p66 } \\
\hline & & $\begin{array}{l}\text { Phage titre } \\
\text { (PFU/mL) }\end{array}$ & Total amount of PFU/FFR & $\begin{array}{l}\text { Phage titre } \\
\text { (PFU/mL) }\end{array}$ & Total amount of PFU/FFR \\
\hline \multirow[t]{2}{*}{ UVGI treated $(n=12)$} & Mean & $0.00 \mathrm{E}+00$ & $0.00 \mathrm{E}+00$ & $0.00 \mathrm{E}+00$ & $0.00 \mathrm{E}+00$ \\
\hline & SD & $0.00 \mathrm{E}+00$ & $0.00 \mathrm{E}+00$ & $0.00 \mathrm{E}+00$ & $0.00 \mathrm{E}+00$ \\
\hline \multirow[t]{2}{*}{ Untreated $(n=8)$} & mean & $1.00 \mathrm{E}+05$ & $2.00 \mathrm{E}+05$ & $1.33 \mathrm{E}+04$ & $2.66 \mathrm{E}+04$ \\
\hline & SD & $6.50 \mathrm{E}+04$ & $1.16 \mathrm{E}+05$ & $1.15 \mathrm{E}+04$ & $2.02 E+04$ \\
\hline
\end{tabular}

FFR, filtering facepiece respirators; PFU, plaque-forming units; UVGI, ultraviolet germicidal irradiation.

Similar fractions (approximately 1/2000, ie, $2 \times 10^{5} \pm 1.16 \times 10^{5}$ plaque-forming unit (PFU) and $2.66 \times 10^{4} \pm 2.02 \times 10^{4}$ PFU for phage vB_HSa_2002 and $\mathrm{P} 66$, respectively) of the total amounts of phage particles applied (ie, $4 \times 10^{8} \mathrm{PFU}$ and $4 \times 10^{7} \mathrm{PFU}$ for phage vB_HSa_2002 and P66, respectively) were released from untreated masks within the FFR extract solutions after 1 hour shaking (table 1 ). It should be noted that the brief heat-drying phase alone has a germicidal effect. No viable phage particles were recovered after preliminary heat-drying tests carried out on a reduced number of respirators $(n=4)$ with the vB_HSa_2002 phage (see online supplemental material).

\section{Respirator integrity with increasing UVGI doses}

While some structural changes were perceptible, the overall integrity and performance of the respirator was only moderately affected by UVGI dose. Penetration rates for fine particles $(10-300 \mathrm{~nm})$ were on average slightly higher in UVGI-treated compared with non-treated respirators (figure 1A). There was no clear trend between structural changes and UVGI doses. Particle penetration rates remained below $2 \%$ at UVGI doses up to 1200 and $3000 \mathrm{~mJ} / \mathrm{cm}^{2}$, corresponding to 20 and 50 treatment cycles. Note that penetration rates for respirators that have been worn once by healthcare professionals were
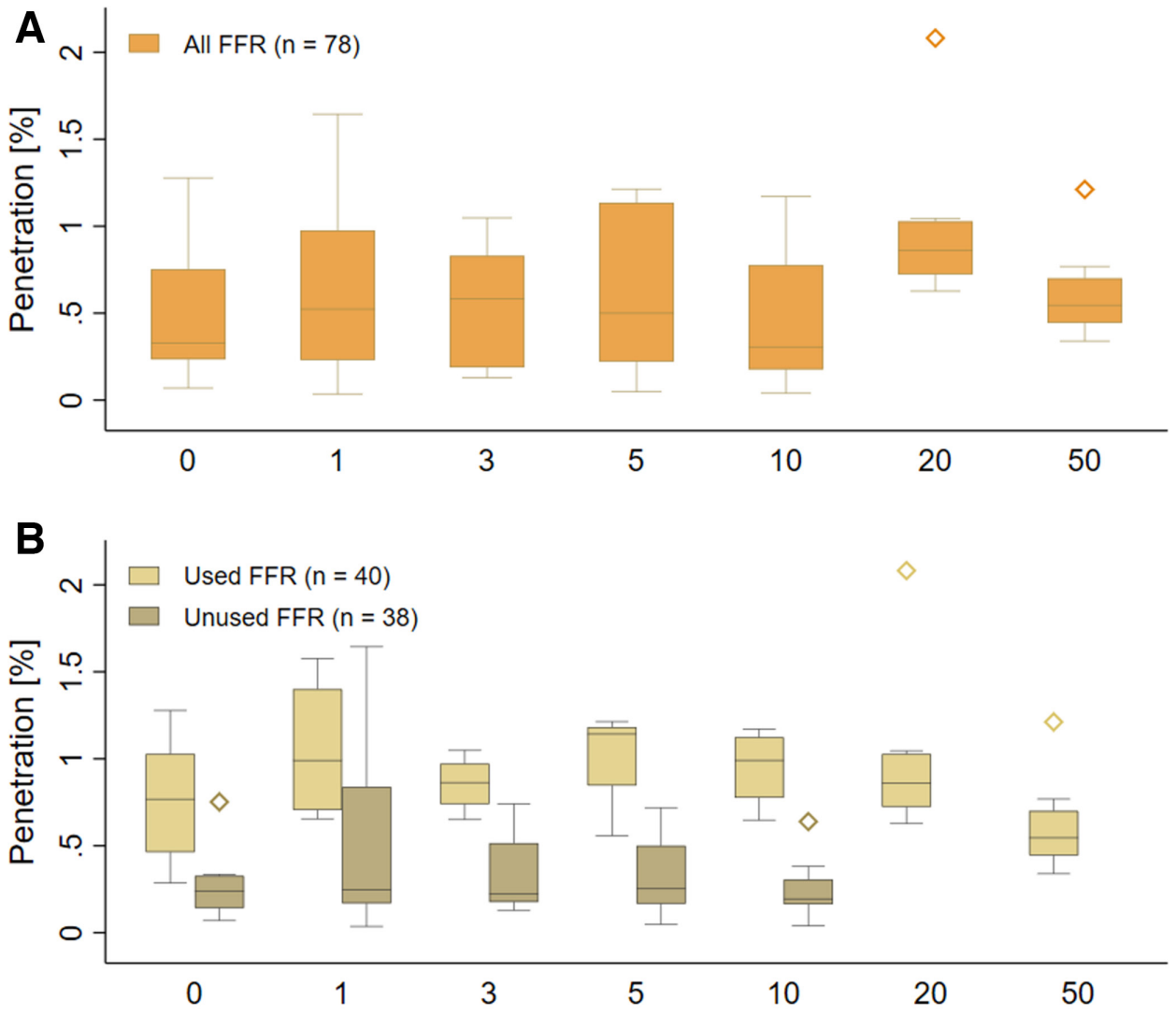

UVGI dose [Equiv. $\mathrm{nb}$ of cycles]

Figure 1 Penetration of fine particles (10-300 nm) through the FFR filter media in \% as a function of the UVGI treatment duration (in equivalent number of cycles): (A) all respirators together and (B) separating unused respirators and respirators used once. FFR, filtering facepiece respirator; UVGI, ultraviolet germicidal irradiation. 


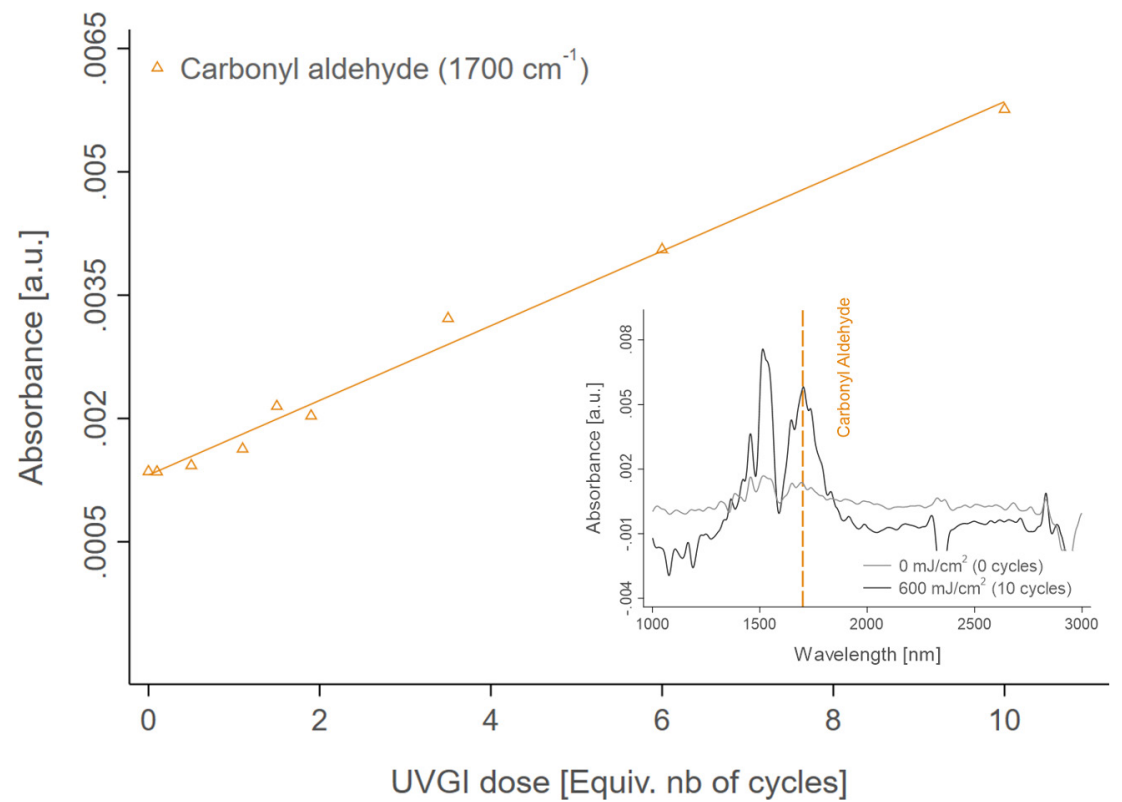

Figure 2 Structural change in the FFR filtering media observed by Fourier-transform infrared spectroscopy as a function of the number of UVGI treatment cycles. In thumbnail, examples of IR absorbance spectrum of the media after 0 and 10 cycles. UVGI, ultraviolet germicidal irradiation.

significantly higher (mean penetration $0.9 \%$ ) compared with unused respirators (mean penetration 0.3\%) (analysis of variance, $\mathrm{p}<0.001$ ) (figure $1 \mathrm{~B}$ ).

An increase of the germicidal UV dose up to 10 cycles $\left(600 \mathrm{~mJ} / \mathrm{cm}^{2}\right)$ did not lead to any visible damage (with the naked eye or by electron microscopy) (see online supplemental material). The stiffness and strain to failure was also not significantly altered, and the crystallinity and melting enthalpy of the respirator material remained identical (see online supplemental material). Structural alterations of the filter media surface were observed with increasing UV dose as increases in aromatic $\mathrm{C}-\mathrm{C}$ bonds $(15201 / \mathrm{cm})$ and carbonyl functions $(17001 / \mathrm{cm})^{2122}$ in the FTIR chromatograms corresponding to the oxidation of polypropylene (figure 2). This change in respirator surface properties could affect particle-surface interception mechanisms, such as direct interception and interception due to Brownian motion.

A generation in reactive oxygen species (ROS) was measured during the UVGI cycle in the exposure chamber air. Ambient hydrogen peroxide $\left(\mathrm{H}_{2} \mathrm{O}_{2}\right)$ levels were determined with photonic-based detection and increased from $35 \pm 31$ (background) to $200 \pm 52 \mathrm{nmol} /$ $\mathrm{L}_{\text {air }}$. Interestingly, the consumption of ozone $\left(\mathrm{O}_{3}\right)$ was observed concomitantly, and $\mathrm{O}_{3}$ concentration fell from $33 \mathrm{ppb}$ for background to $17 \mathrm{ppb}$ after germicidal UV treatment. According to the existing literature on advanced oxidation processes, UV irradiance at 254 $\mathrm{nm}$ triggers the photocatalytic dismutation of $\mathrm{O}_{3}$ into hydroxyl radicals $(\mathrm{HO} \cdot)$ that, in turn, can form more stable airborne $\mathrm{H}_{2} \mathrm{O}_{2}$ molecules. ${ }^{23}$

\section{DISCUSSION}

Two phages were used as model systems to test the efficacy of our decontamination procedure (drying cycle+UVGI) on viral particles infectivity. Indeed, despite these phages being non-enveloped harmless virus models, it has been shown previously that the enveloped (H1N1 and HSV1) and the non-enveloped viruses (eg, DNA murine minute virus) - which are generally more resistant than enveloped viruses-were fully inactivated by a combination of heat and exposure to $17 \mathrm{~mJ} / \mathrm{cm}^{2}$ UVC. $^{24}$ Therefore, a procedure fully inactivating non-enveloped DNA phages would be very likely efficient in inactivating SARS-CoV-2. Our setting allowed recovery in solution of fractions of the applied viable viral particles well above the detection limit of our drop tests assay (ie, $2 \times 10^{2} \mathrm{PFU} / \mathrm{mL}$ ). Our results demonstrated that after a single decontamination cycle, no viable phage particles were recovered from any of the 24 phage-contaminated FFR tested. The developed decontamination procedure successfully inactivated the phage particles and represents therefore a valuable strategy to decontaminate FFR contaminated with SARS-CoV-2. However, it is difficult to precisely quantify its germicidal efficacy due to the detection limit of the method, which is due in particular to the biological material loss during extraction from the respirator in this experiment.

The germicidal efficiency observed for the overall decontamination process is due to both UVGI and heatdrying treatments. As already shown in our preliminary tests and in previous studies, ${ }^{14}$ heat treatment alone has a germicidal effect. However, the UVGI treatment alone is also an effective decontamination method in general and has the advantage of having a broad germicidal action spectrum. Nevertheless, a drying process is required to 
achieve optimal and reproducible UVGI treatment in the depth of the material. By combining the two methods, we propose additional safety by overcoming some of the limitations of each treatment alone and bring convincing arguments for healthcare facilities, which are familiar UVGI treatment.

A drying of $70^{\circ} \mathrm{C}$ during $30 \mathrm{~min}$ and a UV dose of 60 $\mathrm{mJ} / \mathrm{cm}^{2}$ per recycling cycle ensured a germicidal effect without damaging the mechanical and protective properties of the respirator as have been previously published. Although chemical structure changes are measurable on the surface of the filter media at doses below $120 \mathrm{~mJ} / \mathrm{cm}^{2}$ (two cycles), respirator performance assessed as particle penetration across the filtering media was only moderately affected by UVGI treatment. Even after 10 cycles, fine particle penetration remained below the 5\%-6\% thresholds expected for FFP2 or N95 type FFRs.

Our results also show that the wear and tear caused by the use of the respirator affects the penetration performance more than the decontamination procedure itself. This is probably due to the condensation of the user's exhaled breath in the respirator, as high humidity levels have been previously associated with a deterioration of the electrostatic charge of the filtering media. ${ }^{25}$ Tests for multiple reuse cycles were not conducted in this study since recycled respirators can only be used in case of effective shortage, which we did not encounter. These results suggest that respirator performance tests after recycling are necessary. It could be that the number of decontamination cycles are not the limiting factor but rather the number of times the respirator is used.

UVGI treatment and thermal drying are easy to install and relatively inexpensive. Consequently, the decontamination procedure is an interesting alternative in a situation where there is a shortage of disposable respirators. However, the implementation of the decontamination procedure requires some precautions that could limit its germicidal effectiveness such as shading due to the geometry of the respirator and the rapid attenuation of radiation in the filtering media. By using of multidirectional UV sources, controlling the effective radiation dose during treatment, and pretreating the respirator with heat $\left(70^{\circ} \mathrm{C}\right)$, these undesirable effects are avoided. ROS and ozone measurements suggested the presence of $\mathrm{H}_{2} \mathrm{O}_{2}$ concomitantly with the UV treatment. $\mathrm{H}_{2} \mathrm{O}_{2}$ is a gaseous reactive species and can act as a biocidal agent in the depth of the filtering medium giving the UVGI treatment an additional desired effect.

Only one FFP2 respirator brand was used in this study. Similar findings are expected with other FFP2 respirators undergoing UVGI treatment because the filter media are typically polypropylene. There are, however, some caution needed in extrapolating these results to other FFP2 respirator brands, in particular during periods of respiratory supply shortage. Respirators that have not undergone testing and can be of lower quality will then likely appear on the market. For this reason, recycling should be limited to respirators with particularly low penetration rates, typically around $1 \%$. This gives a larger margin of safety with respect to the minimum requirements of the FFP2 and N95 standards.

\section{Author affiliations}

${ }^{1}$ Unisanté, Department of Occupational and Environmental Health, University of Lausanne, Lausanne, Switzerland

${ }^{2}$ Department of Fundamental Microbiology, University of Lausanne, Lausanne, Switzerland

${ }^{3}$ Unit of Forensic Toxicology and Chemistry, CURML, University of Lausanne, Lausanne, Switzerland

${ }^{4}$ Laboratory for Processing of Advanced Composites (LPAC), Institute of Materials (IMX), Ecole Polytechnique Federale de Lausanne, Lausanne, Switzerland

${ }^{5}$ Institute of Public Health, Suranaree University of Technology, Nakhon Ratchasima, Thailand

Acknowledgements We would like to thank Lorenzo Corsini for having kindly provided us with the staphylococcal phage P66. We also would like to thank Dr A Cohades, Dr Y Lebaupin and Ms C Wyss from the Laboratory for Processing of Advanced Composites for performing the Differential Scanning Calorimetry (DSC) and tensile tests.

Contributors DV, GS, AO, NBH, HN-H, NC-L and KB, conceived and designed the study. GS, JS, AO, NC-L, GR, VM, LD-P and NC acquired the data. DV, GS, A0, HN-H, GR and VM contributed to data interpretation and analysis. DV, GR, VM and GS wrote the first draft of the manuscript, and all authors were involved in critical revision of the article and approved the final version for publication.

Funding The authors have not declared a specific grant for this research from any funding agency in the public, commercial or not-for-profit sectors.

Competing interests None declared.

Patient consent for publication Not required.

Provenance and peer review Not commissioned; externally peer reviewed.

Data availability statement Experimental data are available on request from the corresponding author (david.vernez@unisante.ch).

Supplemental material This content has been supplied by the author(s). It has not been vetted by BMJ Publishing Group Limited (BMJ) and may not have been peer-reviewed. Any opinions or recommendations discussed are solely those of the author(s) and are not endorsed by BMJ. BMJ disclaims all liability and responsibility arising from any reliance placed on the content. Where the content includes any translated material, BMJ does not warrant the accuracy and reliability of the translations (including but not limited to local regulations, clinical guidelines, terminology, drug names and drug dosages), and is not responsible for any error and/or omissions arising from translation and adaptation or otherwise.

Open access This is an open access article distributed in accordance with the Creative Commons Attribution Non Commercial (CC BY-NC 4.0) license, which permits others to distribute, remix, adapt, build upon this work non-commercially, and license their derivative works on different terms, provided the original work is properly cited, appropriate credit is given, any changes made indicated, and the use is non-commercial. See: http://creativecommons.org/licenses/by-nc/4.0/.

\section{ORCID iD}

David Vernez http://orcid.org/0000-0002-3304-8727

\section{REFERENCES}

$1 \mathrm{NIOSH}$. Determination of particulate filter efficiency level for N95 series filters against solid particulates for non-powered, air purifying respirators standard testing procedure (STP). Pittsburgh: National Institute for Occupational Safety and Health, 2019.

2 CEN. Respiratory protective devices - Filtering half masks to protect against particles - Requirements, testing, marking. Brussels: European Committe for Standardization, 2009.

3 Siegel JD, Rhinehart E, Jackson M, et al. 2007 guideline for isolation precautions: preventing transmission of infectious agents in health care settings. Am J Infect Control 2007;35:S65-164.

4 Liverman CT, Harris TA, Rogers MEB, et al. Respiratory protection for healthcare workers in the workplace against novel H1N1 influenza A: a letter report. Washington (DC): National Academies Press (US), 2009. 
5 CDC CfDCaP. Coronavirus disease 2019 (COVID-19) decontamination and reuse of filtering facepiece respirators using contingency and crisis capacity strategies 2020. Available: https://www.cdc.gov/coronavirus/2019-ncov/hcp/ppe-strategy/ decontamination-reuse-respirators.html [Accessed 1 Apr 2020].

6 van Doremalen N, Bushmaker T, Morris DH, et al. Aerosol and surface stability of SARS-CoV-2 as compared with SARS-CoV-1. N Engl J Med Overseas Ed 2020;382:1564-7.

7 IOM loM. Reusability of Facemasks during an influenza pandemic. Washington, DC: Facing the Flu, 2006.

8 Heimbuch BK, Wallace WH, Kinney K, et al. A pandemic influenza preparedness study: use of energetic methods to decontaminate filtering facepiece respirators contaminated with $\mathrm{H} 1 \mathrm{~N} 1$ aerosols and droplets. Am J Infect Control 2011;39:e1-9.

9 Lore MB, Heimbuch BK, Brown TL, et al. Effectiveness of three decontamination treatments against influenza virus applied to filtering facepiece respirators. Ann Occup Hyg 2012;56:92-101.

10 Vo E, Rengasamy S, Shaffer R. Development of a test system to evaluate procedures for decontamination of respirators containing viral droplets. Appl Environ Microbiol 2009;75:7303-9.

11 Fisher EM, Shaffer RE. A method to determine the available UV-C dose for the decontamination of filtering facepiece respirators. $J$ Appl Microbiol 2011;110:287-95.

12 Lin T-H, Chen C-C, Huang S-H, et al. Filter quality of electret masks in filtering 14.6-594 $\mathrm{nm}$ aerosol particles: effects of five decontamination methods. PLoS One 2017;12:e0186217-e.

13 Liao L, Xiao W, Zhao M, et al. Can N95 respirators be reused after disinfection? how many times? ACS Nano 2020;14:6348-56.

14 Pascoe MJ, Robertson A, Crayford A, et al. Dry heat and microwavegenerated steam protocols for the rapid decontamination of respiratory personal protective equipment in response to COVID-19related shortages. J Hosp Infect 2020;106:10-19.

15 Su-Velez BM, Maxim T, Long JL, et al. Decontamination methods for reuse of filtering Facepiece respirators. JAMA Otolaryngol Head
Neck Surg 2020. doi:10.1001/jamaoto.2020.1423. [Epub ahead of print: 02 Jul 2020]

16 Rodriguez-Martinez CE, Sossa-Briceño MP, Cortés JA. Decontamination and reuse of $\mathrm{N} 95$ filtering facemask respirators: a systematic review of the literature. Am J Infect Control 2020. doi:10.1016/j.ajic.2020.07.004. [Epub ahead of print: 08 Jul 2020].

17 Viscusi DJ, Bergman MS, Eimer BC, et al. Evaluation of five decontamination methods for filtering facepiece respirators. Ann Occup Hyg 2009;53:815-27.

18 Viscusi DJ, Bergman MS, Novak DA, et al. Impact of three biological decontamination methods on filtering facepiece respirator fit, odor, comfort, and donning ease. J Occup Environ Hyg 2011:8:426-36.

19 Lindsley WG, Martin SB, Thewlis RE, et al. Effects of ultraviolet germicidal irradiation (UVGI) on N95 respirator filtration performance and structural integrity. J Occup Environ Hyg 2015;12:509-17.

20 Lowe JL, Paladino KD, Farke JD, et al. N95 filtering Facepiece respirator ultraviolet germicidal irradiation (UVGI) process for decontamination and reuse. Nebraska Medicine, 2020.

21 MaL C, Tiemblo P, Gómez-Elvira JM. Photo-Oxidation of thick isotactic polypropylene films I. characterisation of the heterogeneous degradation kinetics. Polym Degrad Stab 2000;70:357-64.

22 Yang X, Ding X. Prediction of outdoor weathering performance of polypropylene filaments by accelerated weathering tests. Geotextiles and Geomembranes 2006;24:103-9.

23 Crosley DR, Araps CJ, Doyle-Eisele M, et al. Gas-Phase photolytic production of hydroxyl radicals in an ultraviolet purifier for air and surfaces. J Air Waste Manag Assoc 2017;67:231-40.

24 Firquet S. Inactivation virale par méthodes physiques. Français. ffNNT: 2014LIL2S048ff. fftel-01247888: Université du Droit et de la Santé - Lille II, 2014.

25 Mahdavi A, Haghighat F, Bahloul A, et al. Particle loading time and humidity effects on the efficiency of an N95 filtering facepiece respirator model under constant and inhalation cyclic flows. Ann Occup Hyg 2015;59:629-40. 